\title{
STRATEGIC DECISION SUPPORT FOR URBAN SERVICE DESIGN.
}

\section{Necmiye Yaprak Öz, Halime Demirkan}

\begin{abstract}
The aim of the study is to propose an ontology-based approach that provides a framework as a strategy decision tool for urban service design. The research methodology includes two phases to acquire the knowledge needed for urban service management of a city, as a case study. The first phase provides the priority list, through the Principal Component Analysis, for an age-friendly city determined by the citizens through a quantitative research. The second phase is a qualitative research among the public service providers, focusing on 'adequate community support and health services' feature which was the top priority of phase one. The repertory grid as a mapping tool consists of elements (age-friendly cities' features) and constructs (municipality provided services) that interconnect the tacit knowledge with the external knowledge. The findings indicated the importance of the necessity of a shared understanding and conceptualization of what a service is among service providers and consumers. This paper makes an important contribution to urban service management by making the interconnection between tacit and external knowledge as a strategic decision support tool.
\end{abstract}

Keywords: Decision Making; Service Management; Design Strategy; Public Service; Service Design

\section{INTRODUCTION}

This paper aims to explore the strategic dimensions and drivers of designing knowledge based management with an ontology-based approach in urban service sector. In urban service sector, the main value driver comes from intangible assets. With an intensive knowledge domain, urban service consumers make use of their intangible assets while learning from their previous experiences and create new knowledge as an emerging field of knowledge management (KM). Knowledge management (KM) finds its roots within firms in economic theory (PENROSE, 1959) in the effective allocation of the tangible resources of a firm. An effective KM tool should involve the coordinating mechanism that enables the resources in converting into capabilities of the users (NELSON \& WINTER, 2009). Considering the intangible assets with the tangible ones, KM has recently emerged as a new discipline (DARROCH, 2005, p. 101) for the effective management of knowledge "that enables those within the firm to extract more from all resources available to it". The suitability of the KM strategy and the efficiency of the knowledge support system determine the level of effectiveness and efficiency of the service sector. Most of the developed KM studies provide support for the effective management of knowledge as the use of available resources but none of them explicitly use of tacit knowledge. The relevant studies should go beyond specification of explicit knowledge and unveil the tacit knowledge in KM of urban service design. Therefore, this study develops an ontology-based KM framework as an innovative management tool for decision-making in the urban areas of the age-friendly cities.

\section{AN ONTOLOGICAL STRUCTURE OF SERVICES}

This study proposes a knowledge support system based on ontology to deal with the domain specific knowledge both composed of tacit and external knowledge. In the context of knowledge sharing in service design, 'ontology' means a specification of a conceptualisation (GRUBER, 1993). When the knowledge of a service domain is represented in a declarative formalism, the set of actions that can be represented is called the universe of actions. This set of actions, and the describable relationships among them, are reflected in the representational service model.

As Ferrario et al. (2011 a) stated the term 'service' has a range of definitions in different surroundings. It may indicate an action, a generic type of action or the capability to perform some action. In addition, the term may refer to the result of such an action that may indicate a change affecting an object or a person or to the utility value consequential to the occurred change. In public sector context, the term 'service' indicates organization acting in a specific way for the interest of the public. 


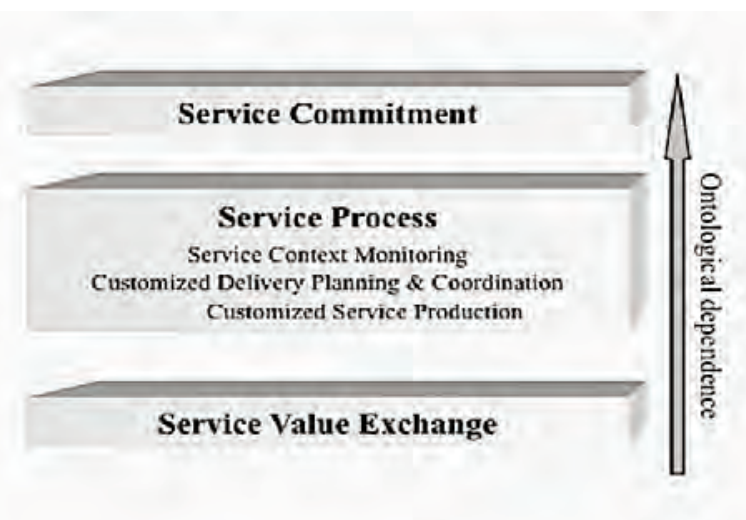

Figure 7. The ontologic structure of service activities. (Source: FERRARIO et al. 201 la: p.243).

Ferrario et al. (201 1 b) stated that an ontological service system model is composed of three main elements; namely, the service commitment, the service process and the service value exchange as seen in (Figure 1). As Ferrario et al. (201 1a) pinpointed in their definition there is a relation of ontological dependence between these main elements. Furthermore, Masolo et al (2003) described in DOLCE ontology, the commitment act starts with the involvement of the service provider and the duration is determined by the commitment's act itself and the fulfillment of the commitment is specified by the provider.

As depicted in (Figure 1), the layers involving the service activities have an ontological dependence relationship. This means in order for an event at a certain layer to occur, some event at the higher level has to occur. Eventually, all the events belonging to the service process presumes the service commitment. Ferrario et al. (2011a, p.245) described the service commitment layer as where the "rules of the game are established". This is the layer that prescribes the characteristics of the service. The types of action that compose the service, the agents that execute the actions, the characteristics of the service providers and consumers and the type of events that trigger the actions should all have to be established in this layer. The service process layer is the implementation level where the consumers of the service (citizens) are involved. In this level also the triggering situation for a specific event should be described. The service production level is characterized as descriptive with all the relevant data quantifiers. The service value exchange is also ontologically dependent on the service commitment layer. Furthermore, it is dependent on the compliance of the service actions being performed during the service process with those defined in the service description that the service provider has committed to. The value of this layer is determined by the level of satisfaction and wellbeing of the citizens with the provided municipality services.

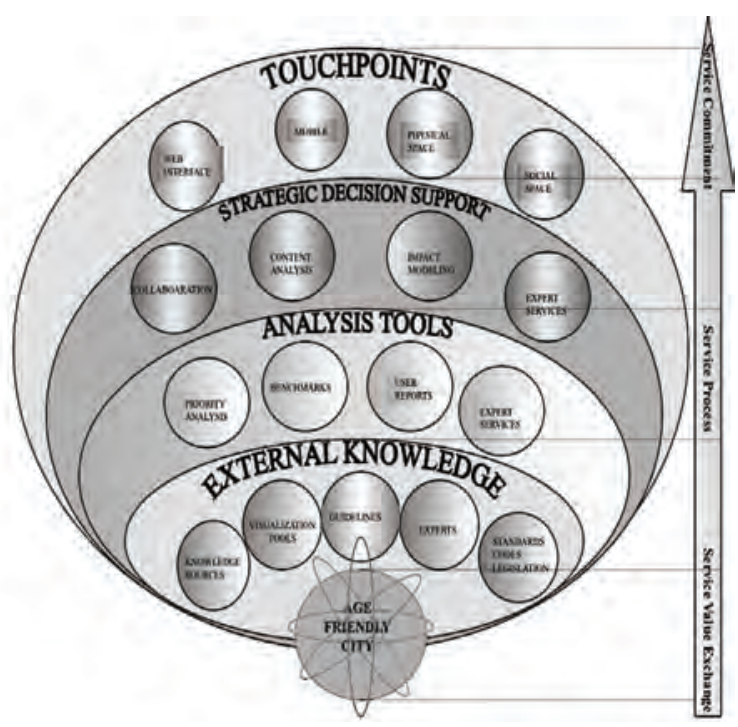

Figure 2. Ontology-based urban service process model. (Source: Authors).

\section{AN ONTOLOGY-BASED URBAN SERVICE PROCESS MODEL}

As depicted in (Figure 1), the core layer of the ontological structure of the service activities is the service process that contains one or many services and complies with the service commitment layer. Participants of the service process are the service provider/s, service consumer/s and service producer/s. In the municipality, the various departments are the service providers where the citizens of the city are the service consumers. Service producers are the ones who actually execute the actions guaranteed by the provider. A public or private organization or an individual could be the service producer. The service producer may not necessarily coincide with the provider. Therefore, municipality departments are the service providers, but not always the service producer.

This paper makes an important contribution to urban service management by making the interconnection between: a) management of citizens (tacit knowledge) and municipality organization knowledge (external knowledge) and b) the management of the service citizens' experience. The literature review related to public service management conducted for the purposes of this study has not revealed any prior attempt that considers the interconnections between these concepts in urban service domain.

The richness of $\mathrm{KM}$ in public service design lies in creating new knowledge instead of just using and sharing existing knowledge. As Nutt (2011) stated for improvement in decision-making research, the content of a decision and strategic and non-strategic choices should be analysed deeply. While 'defining process as action steps, either used in practice or inferred from prescriptions, research can uncover an empirical documentation of action steps' (NUTT, 2011, p.13). 
The urban service model is built upon the three structured layers of the ontological approach that are the service commitment, the service process and the service value exchange (Figure 1). Furthermore, the service process layer is described in three levels consisting of knowledge domain, analysis tools and strategic decision support as seen in (Figure 2).

\section{Service value exchange layer}

This layer is composed of the activities of service providers (municipality departments) and service consumers (citizens). These activities are complementary to each other while developing the value chain. The service value exchange is not a part of the service process and it may actually start before the service provider executes the service as defined in the service description (FERRARIO et al, 2011b). The service value exchange is also ontologically dependent on the commitment as well as the result of a more or less specific compliance of the service actions in the service process.

The first phase of the service value exchange is the service awareness/need awareness phase. It is followed by the initiation decision of the service provider in building the service. In the next step, the service provider presents the service and the consumer searches for a suitable service. Satisfaction level and the wellbeing of the citizens is the value provided as the outcome of the service delivery. Finally, there is the follow up phase that gives feedback to the service provider in ameliorating the services for the future (FERRARiO et al, $2011 \mathrm{~b}$ ). The outcome and follow up phases should be considered in future studies in developing the framework of this study.

\section{Service process layer}

The first level of the service process layer is comprised of the 'knowledge domain' of the service providers and service consumers (Figure 2). Design thinking is an important issue in unravelling, the needs, expectations and desires of all citizens in urban areas (SAVUT \& DEMIRKAN, 2014). These involve knowledge from different media as books, journals or visual sources. Also, observed cases are another source that are the previous experiences of the service providers or consumers. There is a broad body of written documents as standards, references and norms that guide the service providers. Also, there is legislation documents as laws, regulations and by codes that define rights of the citizens. The World Health Organization (WHO, 2007) conducted a research for developing the guidelines of age-friendly cities. As Plouffe and Kalache (2011) highlighted, the themes that were developed by WHO (2007) should be the guidelines in all cities while the implementations of the policy tools should be determined by the local governments.
The second level of the service process layer is the 'tool of analysis'. Analysis tools involve databases, scenario analysis, benchmarking, user reports and expert group analysis. Thirty-three cities were chosen as benchmark cities by WHO (2007) with the support of both governmental and non-governmental organizations and academics. The research showed that there were 82 guidelines under eight main topics. Recently, age-friendly community initiatives were developed in Canada, Spain, Brazil, USA and Australia while deeply focusing on the successful implementations of the age-friendly city guidelines (Age-Friendly NYC: A Progress Report, 2011; GOVERNMENT OF SOUTH AUSTRALIA, TOOLKIT, 2011; SAVUT \& DEMIRKAN, 2014).

The third level in the evolution of KM is marked by citizen-centred approaches that focus on the generation and sharing of new knowledge (Figure 2). This 'strategic decision support' level of the service process layer is viewed as a social process within an environment that fosters collaboration (BORGES, 2012). Transformation of tacit knowledge into explicit knowledge is called the process of externalisation and it determines the success of the urban service sector. Collaboration as a socialization process that focuses on the transmission of tacit knowledge between individuals without the concern of making it explicit is a key issue in urban service KM. Focus of this study is on the collaboration of service providers (municipality departments) with the service consumers (citizens), thus opening the way towards new perspectives in urban service KM. Although BORGES (2012) notified the importance of collaboration among information technology professionals in developing and implementing new systems, the urban service organizations did not pay much attention to this issue in decisionmaking processes.

Simply, the proposed model interconnects the citizens' experiences with the knowledge of municipality employees. A suitable knowledge support system is essential for better-built environments (AFACAN \& DEMIRKAN, 2011 ). Citizens' knowledge is viewed as a part of the municipality's tacit knowledge. Municipality employees' knowledge is the external knowledge. The strength of the proposed urban service $\mathrm{KM}$ model is that it manages both tacit and external knowledge in a holistic approach. Content analysis is a strategic decision support tool for encoding the concept of 'service experience'. As Ferrario et al. (2011 a) stated the service commitment lies at the core of any kind service action(s) delivered by the service provider to the service consumer at a certain cost or wellbeing of an individual, in a certain way at any sitvation. Therefore, the content analysis of the interviews with the municipality employees focuses on service experience that was committed to an individual in the context of a specific event. 
This model uses knowledge in a dynamic way that represents the reflection of citizens' experience to leverage its assets in strategic decision-making into benefits of the citizens. Therefore, urban service KM involves continuous development that is based on the service experiences of the citizens. The service experience of the citizens should be communicated with the employees of the municipality constantly and developed within a holistic approach.

\section{Service commitment layer}

The third layer of the ontological model as the service commitment layer is defined as the 'touch points' of service design (Figure 2). The touch points are the places and spaces where citizens experience the public services. These touch points may involve the physical and social spaces that the public service is provided as recreational, health and educational settings or sports facilities.

In addition, the virtual urban service portals are important touch points for citizens. As Loutas et al. (2011) stated that governments created online portals to enable citizens to find out and utilize specific urban services. Loutas et al. (2011) proposed the Semantic Public Service Portal which structures and stores detailed public services semantically without any complexity in use. This portal provides a rich, structured and personalized public description and provides the relevant service to the citizen.

The premise of this study lies in the effective management of urban service sector that makes use of explicit and tacit knowledge while making interconnections between the two knowledge domains. Therefore, the case study underpins the 'strategic decision support' level of the service process layer in the urban service sector.

\section{STRATEGIC DECISION SUPPORT FOR THE GREATER CITY ANKARA MUNICIPALITY CASE}

This study proposes a strategic decision support tool for determining the interconnection between citizens (tacit knowledge) and municipality organization knowledge (external knowledge). It presents an ontological approach rather than a set of predetermined stages. Although it is not permissible to consider only one layer because of ontological dependence of layers, the case study mainly focuses on the third level of the second layer of the ontological structure model while considering the dependency of layers (Figure 2). The proposed ontological approach intends to help knowledge management designers to navigate in this journey.

The setting of the case study is Ankara, the capital of the Turkish Republic, accommodating approximately 4.8 million citizens according to the latest population research carried out by the Turkish Statistical Institution (2012). The ratio of older age

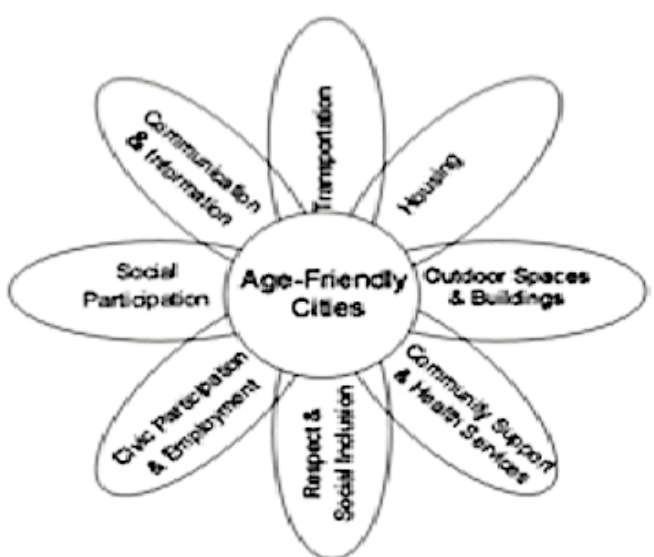

Figure 3. Age-friendly city under eight themes. (Source: Adapted from WHO, 2007, p. 1).

$(65+)$ group living in different districts of Ankara to the total population of the city is $6.89 \%$ (336944 citizens).

\section{METHODS}

The study is conducted in two phases. The first phase determines the features that are the components of the 'age friendly' city (tacit knowledge) based on the needs, wants and desires of the citizens of Ankara. The second phase goes deeply to identify the facilities of the city that provide service; and, the actual decision making and implementation processes (external knowledge) of service providers.

\section{The first phase}

This case study focuses on the welfare of all citizens in 'age-friendly' cities. An 'age friendly' city aims to improve citizens' welfare while enhancing access, quality and delivery of sustainable services in urban areas. Determining the appropriate tools, techniques and methods in identifying the characteristics of the citizens, urban environments and touch points are crucial for the satisfaction and wellbeing of citizens (Figure 2). Since the citizens have diverse physical characteristics and needs, expectations and desires as well as social status, a priority setting should be provided for the diverse population. The focal point in urban service design is the satisfaction and wellbeing of the citizens. Therefore, collaborative approach is appropriate for designing age-friendly cities.

Based on the research that was conducted by WHO (2007), the service value exchange occurs in eight themes at urban settings as depicted in (Figure $3)$. The research presented in this paper is based on these eight themes: namely as outdoor spaces and buildings; transportation; housing; social participation; respect and social inclusion; civic participation and employment; communication and information; and community support and health services.

Firstly, the subjects, who were comprised of 251 citizens of all ages, were asked to complete the 
self-assessment tool that is based on a checklist from the studies conducted in 33 cities by WHO (2007). However, 87 (34.7.3\%) of this sample group were also service providers of some kind to the citizens and 165 (65.3\%) were non-service providers. Among the participants, $83(50.6 \%)$ of the non-service providers and 51 (58.6\%) of the service providers were female. The checklist is composed of 82 items under eight themes as the core features of an age-friendly city (Figure 3). Each local authority is expected to determine its most important core features among these 82 items and work on them with a five-year strategic plan. Therefore, the objective of this phase was to find out which core features were important to specifically the Greater Ankara Municipality, as a case.

In this context, this study proposes a knowledge support system based on ontology to deal with the domain specific knowledge as the tacit knowledge, which involves the priorities of the citizens for an agefriendly city. The ontology of this study's domain is based on the features as 'concept specification' of the eight themes of an age-friendly city, since acquiring tacit knowledge is a very difficult process because of the imprecise and uncertain specifications and different prioritizations of diverse users (AFACAN \& DEMIRKAN, 2010). The importance of each core feature is ranked on a three-point scale from limited contribution to significant contribution $(1$ point $=$ limited/some contribution; 2 points = adequate contribution/satisfactory; 3 points = significant contribution) and 0 is marked as not having any association with a specific feature. The Principal Component Analysis method as the priority analysis tool is conducted for determining the number of factors that are important for an age-friendly Ankara city. The findings of this phase are used to uncover the tacit knowledge.

\section{The second phase}

Firstly, the Greater City of Ankara Municipality organization is analyzed to figure out the departments that are responsible as the service providers to diverse citizens. In this paper, we elaborated on laddering interview as a promising research method for public service research (HERMAN et al., 2000), allowing both for the benefits of qualitative and quantitative research and providing insight in how concrete and tangible service actions are provided and delivered to citizens.

Then, the participants were asked to describe the main services provided to the citizens for 'adequate community support and health' in an age-friendly city. The goal of this first step is to elicit the customized service production from the members of the department. Based on their initial responses relating to services, their delivery plan, coordination and finally monitoring of the service context in service process were asked (Figure 1).

Typical questions for the 'adequate community support and health services' feature as the stated first pri- ority by the citizens are as follows: What are the available services provided by your department within the city? In what type of settings does your department provide the services? How are the services delivered? How do the service consumers access to the information about opportunities on a specific service? How does your department determine the responsiveness of services to individual needs? Are there any changes that could be made to improve the provided service? How does your department achieve these improvements? Is there any possibility of voluntary involvement in any of the services? How does your department provide sustainability of provided services?

For uncovering tacit knowledge in public service design, qualitative approaches are generally required and the personal construct theory provides a structured and explicit method for acquiring the type of data required (EDWARDS et al, 2009; TAN \& HUNTER, 2002). A method and theory suitable to the study of strategic decision in public service design for bridging the gap between the service process of the municipality departments and citizens' needs is Kelly's (1955) personal construct theory and its mapping tool known as the repertory grid. The repertory grid consists of three components: elements, constructs and links. Elements are the main features of the primary factor named as the 'adequate community support and health services' in an age-friendly city. They define the features upon which the administration of the repertory grid is based (Phase 1). Constructs represent the department members' interpretation of the services provided by the municipality (Phase 2). The text obtained during the interviews is investigated both in terms of how citizens' prioritize features and how the services provided by the various departments are connected. This analysis is conducted by two experts within the field and their inter-rater reliability is tested $($ Alpha $=0.91)$. Consequently, the analysis provided the identification of emerging themes from elicited constructs in urban service design.

Bridging the gap between the service process of the municipality departments and citizens' needs and wellbeing is an important yet complex translation process. The translation goes all the way from citizen needs, to service attributes through design, to service implementation and to citizen welfare. This process has traditionally was conducted within two different domains in the previous studies. Using the ontological approach, this study describes the activities for the integration of tacit and external knowledge into a single framework in urban service process.

\section{FINDINGS}

\section{Findings of the first phase}

The factor analysis test was used to group the related features under a factor and to order these features according to their importance. In this way, a list of prioritized factors and their features was obtained as the 


\begin{tabular}{|c|c|}
\hline Adequate community support and health service features & $\begin{array}{l}\text { Features with } \\
\text { loadings } \geq 0.50\end{array}$ \\
\hline $\begin{array}{l}\text { 1. Accessibility to clear information about the health and social services for } \\
\text { older people }\end{array}$ & 0.816 \\
\hline 2. Sevvice accessibility with minimized economic barriers & 0.802 \\
\hline $\begin{array}{l}\text { 3. Service accessibility with respectful and sensitive administrative and } \\
\text { senvice personnel }\end{array}$ & 0.792 \\
\hline 4. Service accessibility with coordinated and simple service delivery & 0.776 \\
\hline $\begin{array}{l}\text { 5. Emergency planning and care that includes older people while taking into } \\
\text { account their needs and capacities in preparing for and responding to } \\
\text { emergencies }\end{array}$ & 0.772 \\
\hline $\begin{array}{l}\text { 6. Service accessibility to all well-distributed health and social services in the } \\
\text { city }\end{array}$ & 0.747 \\
\hline $\begin{array}{l}\text { 7. Service accessibility to residential care facilities integrated to the services } \\
\text { and larger community }\end{array}$ & 0.728 \\
\hline 8. Service accessibility with adequate access to the burial spaces & 0.717 \\
\hline $\begin{array}{l}\text { 9. Offer of services that are conveniently located and accessible by all means } \\
\text { of transportation }\end{array}$ & 0.717 \\
\hline $\begin{array}{l}\text { 10. Offer of sevices that support and encouragement of services by voluntary } \\
\text { citizens of all age }\end{array}$ & 0.693 \\
\hline $\begin{array}{l}\text { 11. Offer of services with provision of home care services including personal } \\
\text { care and housekeeping }\end{array}$ & 0.690 \\
\hline $\begin{array}{l}\text { 12. Offer of services with provision of an adequate range of health and. } \\
\text { community support services }\end{array}$ & 0.680 \\
\hline
\end{tabular}

Table 7. The community support and health services factor with twelve features. (Source: Authors).

elements of further analysis. Initially, a Principal Component Analysis was conducted on the correlations of 82 items. Then, an orthogonal factor rotation was performed using the varimax with Kaiser normalization. The priority list involves six independent factors and one integrated factor as composed of 2 themes (ie. the civic participation and employment theme is integrated with the respect and social inclusion theme). The priority list for the age-friendly city of Ankara with the number of features in parentheses are stated below:

- Adequate community support and health services (12);

- Adequate transportation services (14);

- Civic participation and employment (8); and, respect and social inclusion opportunities (4);

- Adequate communication and information facilities (9);

- Available outdoor spaces and building facilities (7);

- Social participation opportunities (8); and,

- Sufficient and affordable housing services (7).

The primary factor is composed of twelve positively loaded community support and health services features with 0.50 or more loading weights. This study delves deeper in the analysis of the 12 features of the first factor as the case study (Table 1). Further studies were conducted in a similar manner for the other features.

\section{Findings of the second phase}

In the second phase, the researchers determined the objectives of each department of the municipality, related to the features of the community support and health service factor, from their official website (www.ankara.bel.tr/en/) as a sample study. There were

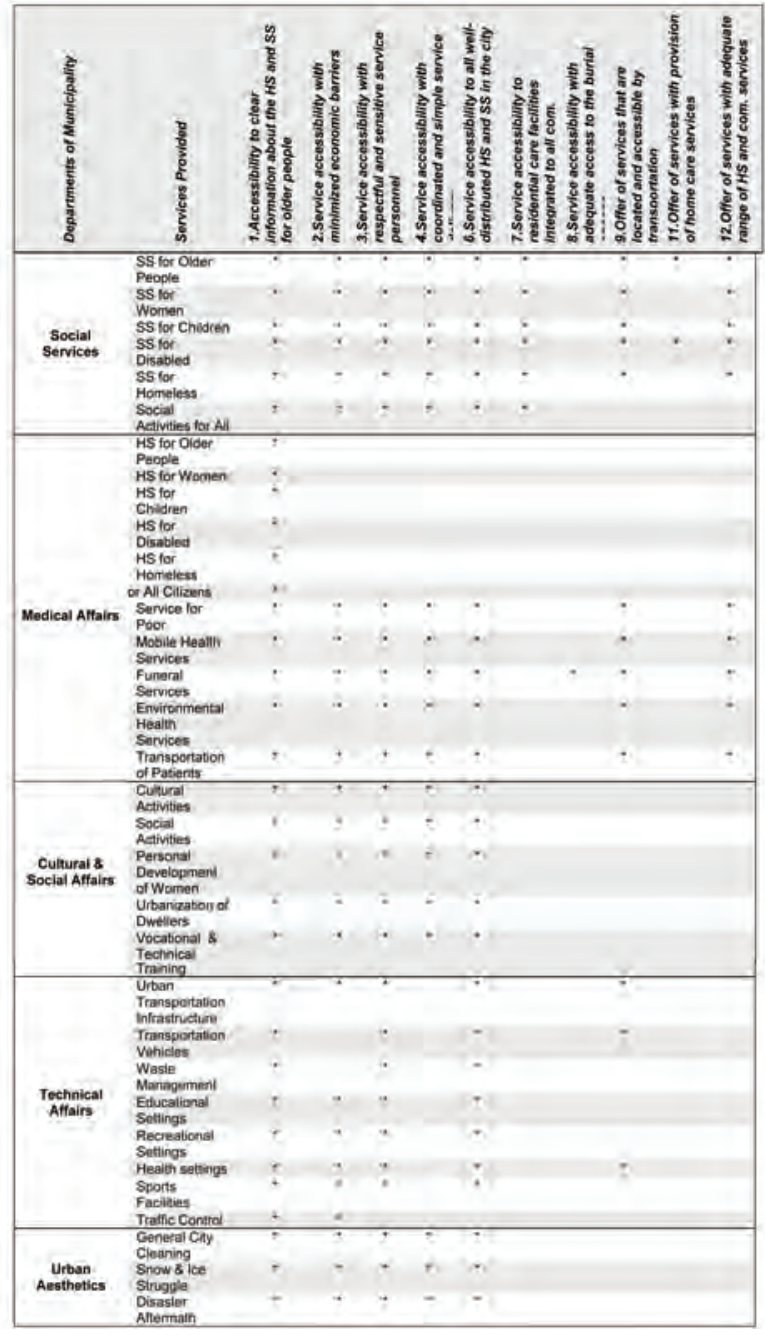

SS: Social Service; HS: Health Service

Table 2. The matrix of the relationship between elements and constructs for primary factor community support and health service. (Source: Authors).

five departments; Social Service, Medical Affairs, Cultural and Social Affairs, Technical Affairs and Urban Aesthetics that include one or more of the features of community support and health primary factor among their objectives. Then, three specialists from each department were invited for an interview in which the adequate community services and health factor were asked as their service provision. The mean of interview length was 23 minutes $(S D= \pm 5.1)$. The information collected from the interviewees was transferred into a matrix in which the twelve features of the primary factor are listed as the elements and the strategic service objectives of the municipality departments as the constructs (Table 2).

It is found out that there was no services planned on the fifth feature which was emergency planning and care that includes older people while taking into account their needs and capacities in preparing for and responding to emergencies. WHO (2007) explained this feature as in case of disasters like earthquakes and floods. The second feature which was not included by any of the departments was the 
tenth feature which asks for offering of the services that support and encouragement of services by voluntary citizens of all ages. Therefore, there are 10 features that are depicted as columns in (Table 2).

The survey conducted among the Ankara citizens in the first phase showed that accessibility to clear information about the health and social services for older people (0.816) is the most important feature of primary factor. During the interviews, all of the participants mentioned about a service provided by the Greater City of Ankara Municipality to access clear information about any services available for all citizens in Ankara. The mentioned service was called "Blue Desk" and the citizens could call \# 153 toll free line to ask any questions they might have. This line works 24/7/365 and the employees of the municipality who answer the line directs the caller to either the related department of the municipality or any other official service providers including the ministries of the state. The Blue Desk is designed as one of the primary touch points of the municipality services but one must put extra effort to make sure that every one knows about this service.

While talking about the second feature of primary factor all the interviewees underlined the fact that municipality charges no fees for the services it provides even though the municipality is not the service producer itself. Furthermore, the Municipality provides economic support to the families of older adults.

The third feature of the primary factor was about service accessibility with respectful and sensitive administrative and service personnel. The Human Resources Department gives internal training services to all the personnel working at the municipality whenever a unit determines that its personnel needs to develop better relationship skills. The matrix shown in Table 2 did not include Human Resources department since their service is not directly to the citizens.

The survey among the service consumers disseminated that the fourth feature of primary factor was service accessibility with coordinated and simple service delivery. This could be an issue among the service providers like the Health Affairs Department of the Municipality and the Ministry of Health.

The interviewees had a consensus on the homogeneity of service distribution in the city, which was found to be the sixth feature of the primary factor. Most of the citizens are learning about these clubs from their member friends and relatives. The interviewees recommended announcing these centres in media more often. On the other hand, this feature will require more personnel to provide the services in these centres, which would be a burden on the Municipality's budget among the other necessary expenses to be met. Therefore, a great amount of the interviewees mentioned that the voluntary participation to these kinds of services should be encouraged by the Municipality, which was the tenth feature of the primary factor. Unfortunately, there is no such activity in the Municipality. The voluntary service system could be coordinated by the Ministry of Education as social responsibility projects starting from secondary schools.

Service accessibility to residential care facili- ties integrated to the services and larger community feature of the primary factor is also found to be related to the Blue Desk service and the centres of the Municipality mentioned above. However, only the Department of Medical Affairs provides service accessibility with adequate access to the cemeteries.

\section{DISCUSSION AND CONCLUSION}

The primary aim of this research was to explore the way in which KM concepts might apply to and facilitate urban service sector in providing services to consumers. Much of the literature relating to this subject focus on the external knowledge domain of the urban service sector. The challenge was to encode, transfer the tacit knowledge and interconnect it with the external knowledge for providing strategies for the service providers. An ontology-based approach is a domainindependent translation tool that does not require the intellectual task of designing ontologies as deciding which concepts and relations to include in the existing knowledge base. Representation ontologies provide a framework, but do not offer guidance about how to represent the services. Furthermore, content ontologies make claim about how the concepts of the services should be described.

We have conducted analysis on the priorities of the service consumers. The priority analysis takes into account the legal perspective, which is the central with respect to service level agreements. This analysis is a basis for building up the tacit knowledge of the service consumers. The service value exchange layer (Figure 1), where the satisfaction level and the wellbeing of the citizens is built up is determined by the priorities of the citizens for an age-friendly city.

The literature supports variations in the priorities of urban service consumers, as the results of the characteristics of the urban areas that are mainly shaped by the population of that area. While all of these models are useful, we believe that each urban area needs to prioritize its developmental initiatives according to that specific area. For Ankara municipality, the primary factor was composed of the community support and health services features. Research conducted in various urban areas could focus on other themes: namely as outdoor spaces and buildings; transportation; housing; social participation; respect and social inclusion; civic participation and employment; or communication and information initiatives.

Another aim was to provide an analytical framework in which all the layers of the ontological model are defined and evaluated. In this paper, we have proposed a novel framework that aims at representing a common ontological base for service science. The main contribution of this approach is to provide a framework for interconnection between tacit and external knowledge as a strategic decision support tool in urban service process. Furthermore, the case should be repeated at some stage in the future and this study provides a baseline against which progress can be assessed.

This framework is proposed with an understanding that a service is mainly composed of service processes 
whose core actions are delivered by a service producer to a service customer that provides all the capabilities that fulfill the service providers' commitment to a service customer as the satisfaction and wellbeing of a citizen in this context. In concluding, although the data and analysis as currently presented are confined to Ankara municipality, they also carry potentially broader implications for other cities. Finally, based on this preliminary framework of the present paper, many studies could be conducted in which the analysis can be extended and enriched.

\section{REFERENCES}

AFACAN, Y. \& DEMIRKAN, H. (2010) A priority-based approach for satisfying the diverse users' needs, capabilities and expectations: a universal kitchen design case, Journal of Engineering Design, 21 (2): 315-343

AFACAN, Y. \& DEMIRKAN, H. (2011) An ontology-based universal design knowledge support system. Knowledge-Based Systems, 24(4): 530-541

AGE-FRIENDLY NYC: A PROGRESS REPORT (2011) Retrieved September 26, 2013 from New York Academy of Medicine web site: http://www.nyam.org/agefriendlynyc/

BORGES, R. (2012) Tacit knowledge sharing between IT workers: The role of organizational culture, personality, and social environment. Management Research Review, 36(1): 89-108

DARROCH, J. (2005) Knowledge management, innovation and firm performance. Journal of Knowledge Management, 9(3): 101-115

EDWARDS, H.M., McDONALD, S. \& MICHELLE YOUNG, S. (2009) The repertory grid technique: Its place in empirical software engineering research. Information and Soffware Technology, 51(4): 785-798

FERRARIO, R., GUARINO, N. \& FERNÁNDEZ-BARRERA, M. (2011a) Towards an ontological foundation for services science: The legal perspective. In Sartor, G., Casanovas, P., Biasiotti, M., \& Fernández-Barrera, M. (Eds.), Approaches to Legal Ontologies ( pp. 235-258) Netherlands, Springer

FERRARIO, R., GUARINO, N., JANIESCH, C., KIEMES, T., OBERLE, D. \& PROBST, F. (2011 b) Towards an Ontological Foundation of Services Science: The General Service Model. Wirtschaftsinformatik Proceedings 2011 (pp. 674-685)

GOVERNMENT OF SOUTH AUSTRALIA. TOOLKIT (2011) South Australia age-friendly environments and communities. Retrieved September 24, 2013 from South Australia: Government of South Australia web site: http://www.sahealth.sa.gov.au/wps/wcm/connect/AgefriendlyGuidelinesLocalGovernment2012.pdf

GRUBER, T.R. (1993) A translation approach to portable ontologies. Knowledge Acquisition, 5(2): 199-220

HERRMANN, A., HUBER, F. \& BRAUNSTEIN, C. (2000) Market-driven product and service design: Bridging the gap between customer needs, quality management, and customer satisfaction. International Journal of Production Economics, 66(1): 77-96

KELLY, G. A. (1955) The psychology of personal constructs. Volume 1: A theory of personality. New York, WW Norton and Company

LOUTAS, N., LEE, D., MAALI, F., PERISTERAS, V. \& TARABANIS, K. (2011) The semantic public service portal (S-PSP). In Grobelnik, G. A. M., Parsia, E. S. B., De Leenheer, D. P. P., \& Pan, J. (Eds), The Semanic Web: Research and Applications (pp.227-242) Berlin Heidelberg, Springer
MASOLO, C., BORGO, S., GANGEMI, A., GUARINO, N. \& OLTRAMARI, A. (2003) The WonderWeb Library of Fundational Ontologies and the DOLCE ontology. WonderWeb (EU IST project 2001-33052) deliverable D18. LOA-ISTC-CNR.

NELSON, R. R., \& WINTER, S. G. (2009) An Evolutionary Theory of Economic Change. Cambridge, MA: Harvard University Press

NUTT, P. C. (2011) Making decision-making research matter: some issues and remedies. Management Research Review, 34(1): 5-16

PENROSE, E. (1959) The Theory of the Growth of the Firm. Oxford: Oxford University Press

PLOUFFE, L. A. \& KALACHE, A. (2011) Making communities age friendly: state and municipal initiatives in Canada and other countries. Gaceta Sanitaria, 25(Suppl.2), 131-137

SAVUT, N. Y. \& DEMIRKAN, H. (2014) Priority setting for service design in age-friendly cities: The city of Ankara. Proceedings of ServDesign 2014, Lancaster University, Lancaster: UK, pp. 11-22

TAN, F. B. \& HUNTER, M. G. (2002) The repertory grid technique: A method for the study of cognition in information systems. MIS Quarterly, 26(1): 39-57

TURKISH STATISTICAL INSTITUTION (2012) Ankara Providence Population Distribution 2012 . Retrieved January 11, 2013 from www.tuik.gov.tr

WORLD HEALTH ORGANIZATION (WHO) (2007) Global agefriendly cities: a guide. Geneva: World Health Organization

\section{Authors}

\section{Dr. Necmiye Yaprak Öz}

Assistant Professor, Bilkent University, Faculty of Art, Design and Architecture, Department of Interior Architecture and Environmental Design, Ankara, Turkey

Email:neyasa@gmail.com

\section{Prof. Halime Demirkan*}

Professor, Bilkent University, Faculty of Art, Design and Architecture, Department of Interior Architecture and Environmental Design, Ankara, Turkey

Email:demirkan@bilkent.edu.tr

*Corresponding author 
Copyright of Open House International is the property of Open House International Association and its content may not be copied or emailed to multiple sites or posted to a listserv without the copyright holder's express written permission. However, users may print, download, or email articles for individual use. 